\title{
Epistemic Contextualism Defended
}

\section{Robin McKenna}

University of Vienna

rbnmckenna@gmail.com

\begin{abstract}
Epistemic contextualists think that the extension of the expression 'knows' (and its cognates) depends on and varies with the context of utterance. In the last 15 years or so this view has faced intense criticism. This paper focuses on two sorts of objections. The first are what I call the 'linguistic objections', which purport to show that the best available linguistic evidence suggests that 'knows' is not context-sensitive. The second is what I call the 'disagreement problem', which concerns the behaviour of 'knows' in disagreement reports. These may not be the only objections to epistemic contextualism, but they are probably the most influential. I argue that the best current epistemic contextualist response to the linguistic objection is incomplete, and I show how it can be supplemented to deal with the full range of linguistic objections. I also develop a new solution to the disagreement problem. The upshot is that neither sort of objection gives us any reason to reject epistemic contextualism. This conclusion is, in a sense, negative - no new arguments for epistemic contextualism are advanced - but it's a vital step towards rehabilitating the view.
\end{abstract}

\section{Introductory Remarks}

Epistemic contextualists - henceforth, 'contextualists' - think that the extension of the expression 'knows' (and its cognates) depends on and varies with the context of utterance. It used to be thought that contextualism offered us both an attractive solution to the sceptical problem (see DeRose 1995) and a nice explanation of linguistic usage, in particular the observation that the appropriateness of ascribing 'knowledge' depends on the context (see the 'bank cases' in DeRose 1992). These motivations are separate, but they are mutually reinforcing. The solution to the sceptical problem gains independent plausibility from the explanation of linguistic usage, and the explanation of linguistic usage gains philosophical interest from the application to scepticism.

I say 'used to be thought' because the solution to scepticism has been criticised for merely sidestepping the problem (see Kornblith 2000 and Sosa 2000) and the explanation of linguistic usage has been attacked on all sides, with some questioning the data (see 
Buckwalter 2010 and May et. al. 2010) and others accepting the data but providing alternative (non-contextualist) explanations (see Brown 2006, Hawthorne 2004, MacFarlane 2005 and Stanley 2005). This leaves the contextualist in a precarious position. Put bluntly, she either needs to respond to these objections or leave the philosophical stage.

In this paper I focus on two sorts of objections. The first sort (the 'linguistic objections') purport to show that the best available linguistic evidence suggests that 'knows' is not context-sensitive. While contextualists have made some progress with the linguistic objections, I argue that problems remain ( $(1)$. The second sort concerns the behaviour of 'knows' in disagreement reports (the 'disagreement problem'). Contextualist have made little progress with the disagreement problem, and all extant attempts to solve it face serious problems. ${ }^{1}$ My aims in this paper are, first, to show how contextualists can deal with the full range of linguistic objections $(\$ 1)$ and, second, to develop a new solution to the disagreement problem $(\$ 2)$.

Why focus on these particular objections? Because both have been enormously influential. Many reject contextualism because of the linguistic objections and the disagreement problem (see, in particular, Hawthorne 2004, MacFarlane 2005 and Stanley 2004). Consequently, in showing that contextualists can deal with these objections, I deal with the main reason why many reject contextualism. My conclusion is, in a sense, negative - no new arguments for contextualism are put forward - but it's a vital step towards rehabilitating the view.

\section{The Linguistic Objections}

I start with some preliminaries (\$1.1). I then take each linguistic objection in turn (\$1.21.4). I argue that, while Michael Blome-Tillmann (2008) shows how contextualists can deal with the first objection, his attempt to deal with the second objection runs into problems, and is of no use in dealing with the third objection. I develop alternative solutions to the second and third objections. The conclusion is that the linguistic objections provide no reason to reject contextualism.

\footnotetext{
${ }^{1}$ See Montminy (2013). I briefly discuss the best-known attempt - DeRose's (2009: Ch. 4) single-scoreboard semantics - below (fn. 14).
} 


\subsection{Preliminaries}

Contextualists think that the extension of the expression 'knows' (and its cognates) depends on and varies with the context of utterance, in much the same way that the extension of other context-sensitive expressions ('I', 'that', 'tall') depends on and varies with the context. Consequently, 'knowledge' ascriptions and denials - instances of 'S knows $p$ ' and 'S doesn't know $p$ ', where ' $S$ ' is a subject and ' $p$ ' some proposition - express different propositions and have different truth-conditions in different contexts. I can remain neutral on how best to implement the view within a formal semantics. However, throughout I'll rely on a particular implementation, on which an instance of 'S knows $p$ ' is true in context c iff S's epistemic position with respect to $p$ is strong enough to meet the epistemic standards operative in c. The operative epistemic standard is determined by various features of the context. Particular epistemic standards are points on a scale, with the strictest standard at one end, and the laxest standard at the other (see DeRose 1995).

Contextualists have often supported their view by appeal to linguistic evidence. The thought is that contextualism provides a nice explanation why it seems that the appropriateness of ascribing 'knowledge' often depends on the context. So, if there were linguistic evidence that 'knows' is not context-sensitive, that would be a problem for contextualism. John Hawthorne (2004) and Jason Stanley (2005) have argued that there is a lot of evidence that 'knows' is not context sensitive. Stanley's stated aim is to show:

"[T] hat the alleged context-sensitivity of knowledge ascriptions has no other parallel among the class of uncontroversial context-sensitive expressions" (2005: 47).

From the outset I want to be clear about the dialectic. None of the linguistic objections, whether taken individually or together, show that 'knows' is definitely not contextsensitive, and neither Hawthorne nor Stanley claim otherwise. Even if Stanley is right, it could be that 'knows' is sui generis, unlike any other context-sensitive expression. But if the contextualist is forced to posit sui generis context-sensitivity, she's in real trouble, especially because there are other views that can account for the linguistic usage that provides some support for contextualism. My aim in the rest of this section is to show that, in certain respects, 'knows' behaves much like other context-sensitive expressions. The critic who wants to reject contextualism based on the linguistic evidence needs to show that any differences are more important than the similarities. 


\subsection{The Gradability Objection}

The first linguistic objection concerns the common contextualist claim that 'knows' is analogous to gradable adjectives such as 'tall' and 'flat' (see DeRose 1995 and Cohen 1999). On a widely accepted account, the extension of a gradable adjective is relative to a contextually provided scale. For example, the extension of 'tall' is relative to a contextually provided scale of height (see Kennedy 1999). Similarly, the idea is that the extension of 'knows' is relative to a contextually provided epistemic standard.

However, as Stanley (2005: Ch. 2) points out, 'knows' isn't gradable. Compare and contrast:

(1) $\mathrm{x}$ is completely/very/quite flat $\mathrm{x}$ is flatter than $\mathrm{y}$

(2) *x completely/very much/quite knows $p^{2}$ $*_{\mathrm{x}}$ knows $p$ more than $\mathrm{y}$

Gradable adjectives accept various degree modifiers ('completely/very/quite') and comparative constructions. But 'knows' doesn't accept degree modifiers or comparatives. Consequently, 'knows' isn't analogous to gradable adjectives. Call this the 'gradability objection'.

Blome-Tillmann (2008: 43) notes that the objection assumes the following:

GRADABILITY: Expressions that are semantically linked to a scale are gradable along that scale.

From GRADABILITY, and the observation that 'knows isn't gradable, it follows that 'knows' isn't semantically linked to a scale. But should we accept GRADABILITY? Blome-Tillmann argues that, once we consider a range of other expressions, it becomes clear that we should reject it. In what follows I outline his argument and explain why it suffices to deal with the gradability objection.

The first is the expression 'snoring'. It's late and I'm in the library. After a while I start sleeping, and so am breathing a little heavier than normal. A hard-working student passes by and says 'He is snoring. I wish he would stop!'. Intuitively, what the student says is true. But if I were to make the exact same sounds in some other context - while sleeping in bed, say - my partner, lying beside me, may well say 'He isn’t snoring. He's just asleep'. Again, intuitively, what my partner says is true. So it's plausible that 'snoring' is context-sensitive.

\footnotetext{
${ }^{2} \mathrm{I} \mathrm{use}^{\text {'*' }}$ to indicate ungrammaticality.
} 
Keeping things rather rough, a contextualist semantics for 'snoring' claims (statements of the form ' $\mathrm{x}$ is snoring') might look something like this:

SNORE: ' $\mathrm{x}$ is snoring' is true in context $\mathrm{c}$ iff ( $\mathrm{x}$ is asleep and $\mathrm{x}$ 's breathing takes a value on a scale of loudness that is greater than or equal to the minimum required to count as 'snoring' in c) (Blome-Tillmann 2008: 45).

The second is the expression 'shouting'. Again, I'm in the library, but this time I'm eagerly discussing Naming and Necessity with a colleague. I raise my voice to a level that is too loud for a library. A distracted student says 'That guy is shouting. I wish he would stop!'. Intuitively, what the student says is true. But if I were to raise my voice to the exact same level in some other context - in the pub, say - and someone were to hear me, they may well say 'That guy isn't shouting. He's just having a conversation with his friend'. Again, intuitively what they say is true. So it's plausible that 'shouting' is context-sensitive. Keeping things rather rough, a contextualist semantics for 'shouting' claims (statements of the form ' $\mathrm{x}$ is shouting') might look something like this:

SHOUT: ' $x$ is shouting' is true in context $c$ iff the volume of $x$ 's voice on a scale of loudness is greater than or equal to the minimum required to count as 'shouting' in c.

However, neither 'snoring' not 'shouting' are gradable along a scale of loudness:

(3) $*_{x}$ is completely/very/quite snoring $\mathrm{x}$ is snoring more than $\mathrm{y}$

(4) $*_{x}$ is completely/very/quite shouting $\mathrm{x}$ is shouting more than $\mathrm{y}^{3}$

There are two options: we can reject GRADABILITY, or we can reject SNORE and SHOUT. But the first option is far more attractive. First, both SNORE and SHOUT are extremely plausible. Second, while neither 'snoring' nor 'shouting' accept degree modifiers or certain comparatives, both accept constructions that serve to rank individual acts of snoring and shouting according to their degree of loudness (adverbial modifiers and comparatives):

(5) $\mathrm{x}$ is snoring very/quite/extremely loudly $\mathrm{x}$ is snoring more loudly than $\mathrm{y}$

\footnotetext{
${ }^{3}$ While the second constructions are both felicitous, they have to be read as $\mathrm{x}$ is snoring more frequently than $\mathrm{y}$ and $\mathrm{x}$ is shouting more often than $\mathrm{y}$, rather than as $\mathrm{x}$ is snoring more loudly than $\mathrm{y}$ and $\mathrm{x}$ is shouting more loudly than $\mathrm{y}$.
} 
(6) $\mathrm{x}$ is shouting very/quite/extremely loudly

$\mathrm{x}$ is shouting more loudly than $\mathrm{y}$

This, as Blome-Tillmann points out (2008: 46), suggests an alternative to GRADABILITY:

GRADABLE OR ADVERBIALLY MODIFIABLE: Expressions that are semantically linked to a scale are either gradable or adverbially modifiable along that scale.

I conclude that the best option is to reject GRADABILITY and accept GRADABLE OR ADVERBIALLY MODIFIABLE.

Returning to the expression 'knows', it seems clear that it accepts a wide range of adverbial modifiers and comparatives (see Blome-Tillmann 2008: 46 and DeRose 2009: 182):

(7) $\mathrm{x}$ knows $p$ with quite/very/extremely good evidence/justification

$\mathrm{x}$ knows $p$ with better evidence/justification than $\mathrm{y}$ knows that $p$

$\mathrm{x}$ knows $p$ with (absolute) certainty

$\mathrm{x}$ knows $p$ with more certainty than $\mathrm{y}$ knows $p$

$\mathrm{x}$ knows $p$ by any reasonable standard

$\mathrm{x}$ knows $p$ by a more reasonable standard than $\mathrm{y}$ knows $p$

Consequently, the gradability objection gives us no reason to conclude that 'knows' isn't semantically linked to a scale. On the contrary, if we accept GRADABLE OR ADVERBIALLY MODIFIABLE, we have reason to conclude that 'knows' is semantically linked to a scale. Further, it looks like there are expressions that, at least in certain respects, behave analogously to 'knows', viz. expressions like 'snores and 'shouts'. I conclude that the contextualist can deal with the gradability objection.

\subsection{The Clarifying Devices Objection}

The second objection concerns what are often called 'clarifying devices'. Compare and contrast:

(8) $\mathrm{x}$ is roughly flat $\mathrm{x}$ is approximately flat

$\mathrm{x}$ is flat for a table

(9) *x roughly knows $p$

$*_{x}$ approximately knows $p$ 
$\mathrm{x}$ knows $p$ by strict/loose standards. ${ }^{4}$

If one makes a claim involving a context-sensitive expression, one can utilise certain constructions - clarifying devices such as 'roughly' or 'approximately' - to clarify what one meant in the face of challenges to one's claim. However, (Hawthorne 2004: 104-8 and Stanley 2005: 69) have argued that 'knows' doesn't accept clarifying devices. Absent a good explanation why, this gives us reason to be wary of contextualism about 'knows'. Call this the 'clarifying devices objection'.

Blome-Tillmann (2008: 50-2) has also developed a response to this objection. The thought is that 'knows' doesn't accept clarifying devices because knowledge is both factive and the norm of assertion. In what follows I, first, expand on this thought and explain why I think it creates new problems and, second, propose an alternative response to the clarifying devices objection.

Consider the following situation. First, Ailsa says (truly) 'Morven knows the bank is open on Saturday'. Second, Laurie raises the epistemic standards to a level such that she can (truly) say 'Morven doesn't know the bank is open'. Now, if there were clarifying devices for 'knows', one would expect Ailsa to be able to utilise them to deal with Laurie's challenge. Using 'by X standards' as a dummy for a proposed clarifying device for 'knows', one would expect Ailsa to be able to say 'I only meant that Morven knows the bank is open by $\mathrm{X}$ standards'. If one asserts that someone 'knows $p$ ', one is committed to $p$ ('knows' is factive). But if in asserting a sentence T one commits oneself to $p$, one must assert T only if one currently 'knows' $p$. Why? Because of the following extension to the 'standard' knowledge norm of assertion:

STANDARD KNOWLEDGE NORM: One must: assert $p$ in context $C$ only if one satisfies 'knows p’ in C (DeRose 2009: Ch. 3; Williamson 2000: Ch. 11).

EXTENDED KNOWLEDGE NORM: Where $\mathrm{T}$ is a sentence that, when uttered in context $\mathrm{C}$, commits the speaker to $p$, one must: assert $\mathrm{T}$ in $\mathrm{C}$ only if one satisfies 'knows $p$ ' in $\mathrm{C}$.

\footnotetext{
${ }^{4}$ As Ludlow (2005) notes, this construction is perfectly felicitous. But, as Stanley (2005: 69-70) points out in response, we also say things like 'France is hexagonal by loose standards'. While expressions like 'by strict/loose standards' might perform some interesting function, that doesn't tell us anything about the context-sensitivity of the expression 'knows' (or 'hexagonal').
} 
So, once Ailsa has been challenged, she can no longer properly say that Morven 'knows' the bank is open by X standards (or that Morven 'knew' by X standards) because she doesn't currently 'know' the bank is open. Consequently, because knowledge is factive and the norm of assertion, one shouldn't expect there to be clarifying devices for 'knows'. Blome-Tillmann concludes that the clarifying devices objection provides no reason to reject contextualism.

Note that this result doesn't follow from STANDARD KNOWLEDGE NORM. All that follows from STANDARD KNOWLEDGE NORM is that Ailsa can properly assert that Morven 'knows' the bank is open by X standards only if she 'knows' Morven 'knows' the bank is open by $\mathrm{X}$ standards, which is consistent with Ailsa not 'knowing' the bank is open by current standards. I think there are good reasons to be suspicious about appealing to EXTENDED KNOWLEDGE NORM in order to deal with the clarifying devices objection (I give them below). Given that there are good reasons to be suspicious, it's problematic if the contextualist response to the clarifying devices objection relies on EXTENDED KNOWLEDGE NORM.

The first reason is just that EXTENDED KNOWLEDGE NORM is a contentious thesis, and all else being equal contextualists would be better off not being committed to it. The second reason is that EXTENDED KNOWLEDGE NORM won't help with the next linguistic objection, whereas the solution to the clarifying devices objection I develop below will. The third and most important reason is that, prima facie, EXTENDED KNOWLEDGE NORM is too strong. Consider this case:

MAFIOSO: Sebastian has decided to have his business partner Cameron killed. Sebastian hires an assassin for this task, Joey. In order to verify that Cameron has been killed, Sebastian requests that Joey wear a hidden camera while she carries out her task. Sebastian settles down to watch Joey in action and is happy to see that everything goes smoothly. However, unbeknownst to Sebastian, there was an unfortunate mix-up: he was actually watching a video of another assassination, and because the man being assassinated looked very like Cameron he didn't notice. While Sebastian was watching this video, Joey was carrying out her task successfully. Later, while reflecting on his actions, Sebastian says 'I regret that Cameron is dead, but it had to be done'.

Given the set-up of MAFIOSO, Sebastian doesn't satisfy 'knows Cameron is dead' in his context (it's a Gettier case). Therefore, by EXTENDED KNOWLEDGE NORM, Sebastian's assertion of 'I regret that Cameron is dead' is improper. But, prima facie, Sebastian's 
assertion is perfectly proper. Cameron is dead, he's dead because Sebastian ordered his assassination, and Sebastian regrets that he had to take this course of action. Even by the lights of EXTENDED KNOWLEDGE NORM, Sebastian could perfectly properly assert that he regrets he had to order Cameron's assassination. It would be bizarre to accept all that but deny that Sebastian can properly assert that he regrets Cameron is dead. Importantly, note that STANDARD KNOWLEDGE NORM does not, by itself, rule that Sebastian's assertion was improper. If one can 'know' one regrets that $p$ without 'knowing' $p$, then, as far as STANDARD KNOWLEDGE NORM is concerned, Sebastian's assertion is perfectly proper. ${ }^{5}$ While this is not a decisive objection to EXTENDED KNOWLEDGE NORM, it puts a lot of pressure on the contextualist who wants to appeal to it to deal with the clarifying devices objection. If there is an alternative solution available, contextualists should avail themselves of it. As I'll now argue, there is.

In $\$ 1.2 \mathrm{I}$ argued that 'knows' accepts various adverbial modifiers and comparative constructions. It seems clear that these constructions can function as clarifying devices. Take the construction 'know by any reasonable standard'. Consider these dialogues:

(10) Morven: I know I have hands.

Laurie: Really? I did a philosophy class once and we talked a lot about the possibility that we're all handless brains in vats. Can you rule that out?

Morven: Seriously? I didn't mean that I know with absolute certainty. I just meant that I know by any reasonable standard.

(11) Ted: I know the bank is open on Saturdays.

Polly: Really? You didn't actually check the opening hours! You need far more evidence.

Ted: Seriously? I didn't mean that I know with absolute certainty that the bank is open. I just meant that I know by any reasonable standard. After all, I do remember going there on a Saturday two weeks ago.

Both dialogues strike me as perfectly natural. In (10) Morven claims to 'know' something (that she has hands) and, in response, Laurie raises an error-possibility. Morven utilises a clarifying device in order to deal with Laure's challenge. Similarly, in (11) Ted utilises the same clarifying device in order to deal with Polly's challenge.

\footnotetext{
${ }^{5}$ I think MAFIOSO is good reason to deny that one has to know $p$ in order to know that one regrets that $p$.
} 
While both dialogues seem natural, it would be nice to have an explanation of what's going on here. Why does 'knows' accept these sorts of clarifying devices? The answer, I think, has to do with how the extension of 'knows' is determined in a context. On a way of thinking about contextualism inspired by David Lewis (see his 1979 and 1996), contextualists think that the extension of 'knows' depends on various features of the conversational context, and in particular the various conversational moves made by those in the context. The idea is that in each context these moves determine the epistemic standard that is 'in play'. There are a wide range of standards that speakers can use, and it is the course of the conversation that determines what the standard is in each context. We can think of speakers as making their conversational moves with some standard or set of standards in mind, and their moves are intended to get those standards accepted by their interlocutors.

Now say that we have a context, like (10) or (11), where one speaker has claimed that a subject S 'knows' $p$. This speaker - call her A - will have had some standard or set of standards in mind when she made her claim. If another speaker - call her B - raises a hitherto unmentioned error-possibility that $S$ is unable to rule out, $A$ has a number of options. Here are three (no doubt there are others). First, A could take that error-possibility seriously, and so the epistemic standards will rise to a level such that $\mathrm{S}$ no longer 'knows' p. In that case, B 'wins', in that her standard gets accepted by both A and B. Second, A could ignore the error-possibility, and try to get B to do so too. If she is successful, A will 'win', and the epistemic standards will stay more-or-less the same (so S will still 'know' that p). Third, A could accept that the error-possibility can't be rejected out of hand, but object that she never intended to say that it could be ruled out. This would involve A making explicit the standard (or, range of standards) that she originally had in mind. For example, as in (10) above, A could clarify that she didn't mean to be making claims about what someone 'knows with absolute certainty'. Rather, she meant to be making a claim about what someone 'knows by any reasonable standard'.

If this sort of picture of how 'knows' acquires its extension in a context is right, it is no surprise that 'knows' accepts a range of clarifying devices. If it didn't, then speakers would face a far more restricted set of options when dealing with a challenge than they in fact

\footnotetext{
${ }^{6}$ Of course, this might not be the end of the process. B might object that A's newly clarified claim still fails to take something important into account. At this point, A has the same set of options (I come back to this point below).
} 
face. So I conclude that, not only can the contextualist give examples of clarifying devices, she can explain why these clarifying devices can be appropriately used.

Before moving on to the next objection, I'd like to pause to make two quick comments about this picture, and deal with an objection. First, the view outlined above has it that the epistemic standard operative in a particular context is determined by a process of negotiation between the various interlocutors in the context. One might wonder whether the relevant standard is just whatever standard the interlocutors happen to agree on, or if there is the further constraint that the standard agreed upon has to be in some sense 'reasonable'. While I want to remain neutral on this question here, my own sympathies are with the view that there is a further constraint. In other work I have argued that we can understand this constraint in terms of the practical environment of those in the context, the idea being that a standard is reasonable in a context just in case it 'fits' the practical environment of those in the context (see McKenna 2014; for similar views see Greco 2008 and Henderson 2009). This view strikes me as right in part because it seems possible that the interlocutors could end up adopting a standard that is completely unreasonable (in the sense that it fits very badly with their practical environment). But, again, I need take no stand on this here.

Second, one might wonder what happens when the interlocutors don't come to an agreement about which standard to use. Speakers can, if they so wish, continue to insist on their own epistemic standards, and refuse to accommodate their conversational partners. What happens in this case? This issue is closely connected to the disagreement problem, so I will revisit it later (see in particular $\$ 2.1 .2, \$ 2.2$ and fn. 14).

Finally, one might worry that some of the modifiers and comparatives mentioned in $\$ 1.2$ 1.3 are problematic for the contextualist because they make reference to epistemic positions and statuses (e.g. 'knowing with good evidence/justification' or 'knowing by a reasonable standard') and one would expect contextualism to go for a range of epistemic positions and statuses other than knowledge. If one adopts this more general sort of contextualism, and one wants to appeal to adverbial modifiers and comparatives to deal with a range of linguistic objections (as I do here), a regress beckons. Speakers are supposed to be able to clarify claims involving one context-sensitive epistemic expression ('knows') by reference to other context-sensitive epistemic expressions (e.g. 'by any reasonable standard'), which themselves may be in need of clarification. Where do such chains terminate? 
Let me make four points in response. First, this is not going to be a problem for any of the comparative constructions ('with better evidence/justification than', 'with more certainty than', 'by a more reasonable standard'). These constructions appeal to epistemic positions that can be had to a greater or lesser degree. Take justification. The contextualist about justification will hold that the context determines how high a degree is required to be justified. But she need not deny that there are absolute facts about whether one belief is more justified than another. Much the same will go for the contextualist about evidence and 'reasonableness' (whether of standards or beliefs). Compare: The contextualist about 'tall' holds that the context determines how high something has to be to count as 'tall'. But she doesn't deny that there are absolute facts about whether one thing is taller than another.

Second, one could restrict one's contextualism to some but not all epistemic positions and statuses. Of the clarifying devices listed, this is most plausible for 'with (absolute) certainty'. One could hold that 'certainty' indicates an absolute status, whether the highest degree of certainty possible, or (perhaps more plausibly) the highest degree of certainty of which limited cognitive beings such as us are capable. Perhaps this is less plausible for the other clarifying devices, but there is no obvious inconsistency in combining contextualism about 'knows' with (for example) invariantism about what makes for good evidence.

Third, it is open to the contextualist about knowledge to give an account of what counts as e.g. a reasonable standard which makes no reference to further epistemic positions or statuses. Greco (2008), Henderson (2009) and McKenna (2014) develop such accounts of what counts as a reasonable standard, the basic idea behind all of which (put roughly) is that whether a standard is reasonable depends on whether it fits the practical environment of those in the context. Note, though, that this sort of move seems less plausible in the case of justification and evidence.

Finally, on the Lewis-inspired contextualist picture outlined above, the regress isn't as threatening as it first appears. Take (10). Imagine that Laurie responds to Morven's attempt to clarify what she meant ('I just meant that I know [by any reasonable standard] that I have hands') by objecting that Morven doesn't even 'know' by any reasonable standard. Again, Morven has at least three options. First, she can give up, and admit that she doesn't 'know' by any standard. Second, she can try to convince Laurie. Third, she can clarify still further: 'what I meant was that I know by a standard that is reasonable for present purposes'. Of course, Laurie can object yet again: why is the standard reasonable for present purposes? While Morven and Laurie seem close to intractable disagreement, I 
don't see why any kind of threatening regress beckons. (Again, I discuss the problem of disagreement below).

While more could be said here, I hope it is clear that the contextualist can say a number of things in response to this objection. I tentatively conclude that it gives us little reason to reject the response to the clarifying devices objection developed in this sub-section.

\subsection{Stanley's Inductive Argument}

The third objection concerns the following generalisation, which Stanley (2005: Ch. 3) argues provides good reason to think that 'knows' isn't context-sensitive:

MULTIPLE OCCURRENCES: Since semantic context-sensitivity is traceable to an individual element (although that element may be unarticulated), multiple occurrences of that element in a discourse should be able to take on differing extensions.

A wide range of context-sensitive expressions behave as the generalisation predicts:

(12) Every sailor waived to every sailor. (Read as: Every sailor on one ship waived to every sailor on another ship).

(13) That mouse is tall, but that elephant is not tall.

(14) That table is flat, and Holland is flat.

(15) This is heavier than this. (Read as: One object is heavier than another object).

(16) Edinburgh has many bagpipers but not many Scots. (Edinburgh has more Scots than bagpipers, but less Scots than is usual for Scottish cities, and more bagpipers).

Once any ambiguity is resolved, (12-16) can be read in such a way that separate occurrences of the various context-sensitive expressions take on different extensions. In contrast:

(17) If they have hands, most non-epistemologists know they have hands, but, even if they have hands, no epistemologist knows she does.

(18) Morven knows she has hands, but she doesn't know she's not a handless brain in a vat.

(19) If the bank is open on Saturdays, I knew the bank is open on Saturdays, but now that you mention the possibility that it has changed its opening hours, even if it is open on Saturdays I don't know it is.

Even once any ambiguity is resolved, it's very hard to read (17-19) in such a way that separate occurrences of 'knows' take on different extensions. Call this 'Stanley's inductive 
argument'. I'm going to argue that contextualists can deal with Stanley's inductive argument by appealing to the availability of clarifying devices for 'knows'. Thus, the solution to the clarifying devices objection developed in $\$ 1.3$ helps here too.

The first thing to note is that the contrast between (12-16) and (17-19) is not that stark. It's not exactly easy to read (12-16) in such a way that separate occurrences of the relevant context-sensitive expressions take on different extensions, and in some cases - (12), 15) and (16) - the preferred reading is supplied via material in parentheses. Absent any background or context, (17-19) aren't much easier (or much harder) to read in such a way that separate occurrences of context-sensitive expressions take on different extensions. So the crucial question if whether providing some background and/or context makes it easier to get the desired readings of (17-19). To test whether it can, we can try putting material in parentheses to indicate a preferred reading. Consider these variants on (17-19):

$\left(17^{*}\right)$ If they have hands, most non-epistemologists know they have hands, but, even if they have hands, no epistemologist knows she does. (Read as: If they have hands, most non-epistemologists know they have hands by any reasonable standard but, even if they have hands, no epistemologist knows she does with absolute certainty).

(18*) Morven knows she has hands, but she doesn't know she's not a handless brain in a vat. (Read as: Morven knows she has hands by any reasonable standard, but she doesn't know she's not a handless brain in a vat with certainty).

(19*) If the bank is open on Saturdays, I knew the bank is open on Saturdays, but now that you mention the possibility that it has changed its opening hours, even if it is open on Saturdays I don't know it is. (Read as: If the bank is open on Saturdays, I knew it is open with quite good justification, but now that you mention the possibility that it has changed its opening hours, even if it is open on Saturdays I don't know it is with extremely good justification).

Once the context/background is supplied, I see no bar to reading $\left(17^{*}-19 *\right)$ in such a way that separate occurrences of 'knows' take on different extensions. Again, this is because 'knows' accepts clarifying devices, so speakers have devices at their disposal for clarifying that separate occurrences of 'knows' within a single discourse or sentence take different

\footnotetext{
${ }^{7}$ Note that the contextualist can't respond by appealing to the fact that knowledge is both factive and the norm of assertion. One can assert (17) or (19) without committing oneself to having hands or the bank being open on Saturdays, and (18) is problematic because it looks like a violation of the closure principle (very roughly, the principle that, if one knows $p$ and one knows if $p$ then $q$, then one is in a position to know $q$ ).
} 
extensions. Because I see no difference between (12-16) and (17-19), I conclude that the contextualist can deal with Stanley's inductive argument. Putting this together with the argument of $\$ 1.2-3$, I conclude that the contextualist can deal with all of the linguistic objections.

To repeat: I take this section to have shown that, in certain respects, 'knows' behaves much like other context-sensitive expressions. The critic of contextualism needs to show that any differences are more important than the similarities. This leads nicely to the disagreement problem, which some think shows that 'knows' behaves very differently to paradigm context-sensitive expressions.

\section{The Disagreement Problem}

Consider the following trio of cases. ${ }^{8}$ Ted and Dougal, who are both priests, have a regular bet on whether Jack will perform his Monday afternoon service. If Jack performs the service, Dougal wins $£ 10$; otherwise, Ted wins $£ 10$. On Monday afternoon they go to the church to check up on Jack. They see his hat in the hallway and they hear that a service is in progress. Satisfied, they leave to go for a drink. At the pub, Ted is asked who won the bet, and he reports that Dougal did. Ted is asked how they 'know' Jack performed the service, and he explains that, given their evidence, he 'knows' that Jack performed the service. ${ }^{9}$ Call this case NORMAL. On their way home Ted and Dougal are stopped by the police. A serious crime has been committed, and the police need to ascertain Jack's whereabouts that afternoon. Ted is questioned first, and he explains that, even though he saw Jack's hat in the hallway and a service was in progress, he doesn't 'know' that Jack performed the service because he didn't actually see him. When Ted is told that he was heard claiming to 'know' in the pub earlier, he says 'I was wrong. I don't know'. Call this case HIGH. Dougal is then questioned, and he also says that neither he nor Ted 'knows' that Jack performed the service. When Dougal is told that Ted was overheard claiming to 'know', he says 'No Ted's wrong. He doesn't know'. Call this case HIGH*.

Ted's 'knowledge' ascription in NORMAL seems appropriate, yet both his denial in HIGH and Dougal's denial in $\mathrm{HIGH}^{*}$ also seem appropriate. This is an instance of a general phenomenon that supports contextualism (see DeRose 1992). However, other features of these cases are more problematic for the contextualist. In particular, in HIGH Ted retracts

\footnotetext{
${ }^{8}$ The cases are inspired by DeRose's 'Thelma \& Louise' cases (2009: Ch. 1).

${ }^{9}$ Assume that Jack did perform the service.
} 
his earlier claim to 'know' ('I was wrong'), and in HIGH* Dougal disagrees with Ted's 'knowledge' self-ascription ('No, Ted's wrong'). If contextualism is true, what Ted said in NORMAL - roughly, that he 'knows' by some not particularly onerous epistemic standard doesn't contradict what he says in HIGH - roughly, that he doesn't 'know' by some very onerous epistemic standard. But, if that's right, why does he say that he was wrong? Similarly, what Dougal says in HIGH* doesn't contradict what Ted said in NORMAL, so why does he seem to disagree with Ted? I'll call this the 'disagreement problem'.

The upshot is that, while contextualists can explain certain features of certain cases, there are other features of those cases, and of other cases, which seem to provide reason to reject contextualism (for similar objections see Hawthorne 2004: 101-4, MacFarlane 2005, Richard 2004 and Stanley 2005: 52-4). Contextualists need to give an explanation of those problematic features. In this section I develop an explanation. In \$2.1 I survey the resources available for dealing with the problem, and I outline what the contextualist would have to do in order to utilise those resources. In $\$ 2.2 \mathrm{I}$ argue that the contextualist can utilise the resources. The upshot is that the disagreement problem provides no reason to reject contextualism.

\subsection{Varieties of Disagreement}

Contextualist semantics have been proposed for a wide range of expressions (deontic and epistemic modals, taste predicates, aesthetic predicates, etc.). But, prima facie, a contextualist semantics is badly placed to handle disagreement. If one thinks that statements within a certain domain make implicit reference to the context in which they are uttered, one is hard pressed to make sense of the idea that there can be genuine disagreement about statements within that domain. Statements that appear contradictory may make reference to different contexts, and so not have incompatible contents (for discussion see, among many others, Brogaard 2008, Stephenson 2007, Stojanovic 2007 and von Fintel \& Gillies 2009). But perhaps this is too quick. Why think that disagreement requires incompatible contents? This raises a further question: When do two people disagree?

I think that the initially attractive view on which two people disagree just in case they utter statements with incompatible contents (or better, have beliefs with incompatible contents) is wrong. To explain why, I'll introduce what I call 'attitudinal disagreement' (\$2.1.1) and what I call 'context disagreement' (\$2.1.2). 


\subsubsection{Attitudinal Disagreement}

Consider these two dialogues:

(20) Frank: I like haggis.

Stephen: No you're wrong. It's too peppery for me.

(21) Frank (aged 10): Yuck. I hate haggis.

Frank (aged 26): I was wrong. I like haggis.

It seems right to say that, in some sense of 'disagree', both Frank and Stephen and Frank and his younger self disagree. Yet it may well be that Stephen accepts that Frank likes haggis, and Frank accepts that he used to hate it. However, Frank and Stephen clearly have incompatible non-doxastic attitudes: Frank couldn't coherently adopt Stephen's attitude towards haggis without abandoning his own, and he couldn't coherently adopt his former attitude towards haggis without abandoning his present attitude. That two people can disagree in the sense that they have incompatible non-doxastic attitudes is a familiar point - familiar from Charles Stevenson (1944) - but it bears repeating here because it demonstrates that two people need not have incompatible beliefs in order to disagree. I'll call this 'attitudinal disagreement'.

This prompts a natural question: Can contextualists about statements within a given domain appeal to attitudinal disagreement to make sense of disagreement about statements within that domain? Torfinn Huvenes (2012) suggests that the contextualist about 'tasty' claims might take this route. Consider these dialogues:

(22) Frank: Haggis is tasty.

Stephen: No you're wrong. Haggis isn't tasty.

(23) Frank (at age 10): Yuck. Haggis is not tasty.

Frank (at age 26): I was wrong. Haggis is tasty.

If the contextualist about 'tasty' holds that claims of the form ' $\mathrm{x}$ is tasty' express a proattitude towards $\mathrm{x}$, whereas claims of the form ' $\mathrm{x}$ is not tasty' express a con attitude, she can give a simple explanation of (22-23). Both Frank and Stephen and Frank and his younger self have incompatible non-doxastic attitudes towards haggis, and Stephen's use of the 'disagreement markers' 'No you're wrong' and Frank's use of the 'retraction markers' 'I was wrong' signals this incompatibility. However, it's important to note that attitudinal disagreement licenses the use of a fairly limited range of disagreement and retraction markers. Compare (22-23) with (24-25): 
(24) Frank: Haggis is tasty.

Stephen: What you said/believe/think is false. Haggis isn't tasty.

(25) Frank (aged 10): Haggis is tasty.

Frank (aged 26): What I said/believed/thought is false. Haggis isn't tasty.

While one may use constructions like 'No' and 'You're (I was) wrong' to signal attitudinal disagreement, one can’t use constructions like 'What you (I) said/think/believe is false’ for this purpose. The moral is that an appeal to attitudinal disagreement only gets the contextualist so much. It deals with some of the disagreement data, but not all.

\subsubsection{Context Disagreement}

Contextualists about 'tall' think that the extension of 'tall' depends on a contextually determined standard of height. This standard is determined in a context via a process of negotiation, and when the speakers reach agreement on a standard it is that standard which determines the extension of subsequent uses of 'tall' in that context. ${ }^{10}$ Subsequent uses of 'tall' will communicate information about the height of various objects. For example, in saying that John is very tall a speaker can communicate that John's height easily meets the contextually determined standard. But what about uses of 'tall' prior to the speakers reaching agreement? Some of these uses serve to make determinate or 'sharpen' the extension of 'tall'. So the speakers in a context might try to sharpen the extension of 'tall' in different directions, as in the dialogue below (taken from Barker 2002):

(26) It's common knowledge between Pieter and Kim that their friend Jaap is a certain height. Eusebio, who is visiting from abroad, is told how tall Jaap is, and he asks them if Jaap counts as tall in the Netherlands.

Pieter: Jaap is tall.

Kim: No, you're wrong. Jaap isn't tall.

Pieter and Kim's uses of 'tall' serve to sharpen its extension, not to communicate new information (Jaap's height is common knowledge). But, because Pieter and Kim are trying to sharpen its extension in different directions - Pieter is proposing that the standard be such that Jaap meets it, Kim is proposing that it be such that Jaap doesn't - it's natural to describe Pieter and Kim as disagreeing.

\footnotetext{
${ }^{10}$ This picture is similar to the picture of how contextualism about 'knows' works outlined in \$1.3. Again, in both cases the inspiration is Lewis (1979).
} 
That two people can disagree in the sense that they disagree about how to sharpen the extension of a context-sensitive expression is a less familiar point, but it's equally worth bearing in mind. I'll call this 'context disagreement' (because, put roughly, the disagreement is over what the context is like). ${ }^{11}$ Again, this prompts a question: Can contextualists about statements within a given domain appeal to context disagreement to make sense of disagreement about statements within that domain ${ }^{12}$ Importantly, note that this would have a pay-off for the contextualist. Unlike attitudinal disagreement, context disagreement licenses the use of a wide range of disagreement markers and, in particular, 'What you said/think/believe is wrong'. To see this consider this variant on (26) (using the same setup):

(27) Pieter: Jaap is tall.

Kim: What you said/think/believe is wrong. Jaap isn't tall.

Kim's response seems as natural in (27) as it does in the original (26).

One might wonder whether context disagreement can make sense of disagreement across contexts as well as disagreement within contexts. To see why, note that I have introduced context disagreement via observations about how the extensions of context-sensitive expressions are sharpened within a particular context. However, I see no reason not to think that context disagreement can handle cases of disagreement across contexts too. Consider another variant on (26) (again, same setup):

(28) It's the next day, and Kim is recounting her argument with Pieter to her friend Annika. It's also common knowledge between Kim and Annika that Jaap is a certain height. After some discussion Annika says that she thinks that Jaap does count as tall in the Netherlands, so she agrees with Pieter. And, while she takes some convincing, Kim eventually decides that Pieter probably was right. Concluding, Kim says 'I was wrong. Jaap is tall'.

It's important to recognise that the processes of negotiation via which the extension of a term is determined in one context can have an impact on the processes of negotiation via which the extension of that same term is determined in another context. This shouldn't be

\footnotetext{
${ }^{11}$ I take the label 'context disagreement' from Sundell (2011), but the basic idea is from Barker (2002).

${ }^{12}$ Sundell (2011), for instance, appeals to context disagreement in defence of contextualism about matters of taste (including the aesthetic).
} 
surprising. Given how often we need to engage in negotiation, it would be both pointless and a waste of time to start from scratch on each occasion. Take, for example, (28). Kim refers Annika to her previous conversation with Pieter, and she proposes that her and Annika use 'tall' in the way in which she proposed using it in that conversation. However, as (28) progresses Annika proposes that they use 'tall' differently, and after a while Kim agrees. This leads her to retract her earlier claim that Jaap isn't 'tall', and in doing so she is signalling her disagreement with the way in which she proposed using 'tall' in (26), and the way in which she initially proposed using it in (28). Kim disagrees with her past self as to how to sharpen uses of 'tall' in both her present context, i.e. (28), and the earlier context, i.e. (26). So both retraction and disagreement markers can be used to signal context disagreement.

Summing up, two people need not have incompatible beliefs in order to disagree. They may have incompatible non-doxastic attitudes (attitudinal disagreement), or they may disagree about how to sharpen the extension of a context-sensitive expression (context disagreement). So the natural question is: What does the contextualist about 'knows' need to do in order to appeal to attitudinal disagreement or context disagreement (or perhaps both) in order to solve the disagreement problem? In what follows I will argue that the answers are as follows. For attitudinal disagreement, she needs to identify a non-doxastic attitude that is plausibly pragmatically expressed by 'knowledge' ascriptions, and that nondoxastic attitude needs to explain our intuition that Dougal disagrees with Ted in HIGH*, and our intuition Ted disagrees with himself in HIGH. For context disagreement, she needs to show that disagreements about the application of the expression 'knows' are analogous to our paradigm cases of context disagreement, (26-28). I now turn to these tasks.

\subsection{Recommendations and Disagreement}

I start with the pragmatic function of 'knowledge' ascriptions. My claim is that 'knowledge' ascriptions pragmatically function as recommendations. If I say 'S knows $p$ ' I recommend S as a source of information as to whether $p$. But why think that 'knowledge' ascriptions serve this function?

First, that they do so is prima facie plausible. If I am looking for some information - I want to find out whether the restaurant accepts credit cards, say - and you identify your friend as someone who 'knows' that the restaurant accepts credit cards, then in doing so you are recommending your friend to me as someone with information as to whether the restaurant accepts credit cards. Presumably you're doing something else as well - you have 
expressed a proposition with truth-conditions etc. - but, in addition, you have recommended your friend to me. Second, a number of epistemologists endorse the claim that 'knowledge' ascriptions serve this pragmatic function (or, at least, a pragmatic function that's similar enough for my purses): see, for instance, Miranda Fricker (2008, 2012), John Greco (2008, 2009), Christoph Kelp (2011), Jennifer Lackey (2012), Ram Neta (2006) and Duncan Pritchard (2012). The claim is usually defended by reference to Edward Craig (1990), who introduces and motivates it as follows:

"Human beings need true beliefs about their environment, beliefs that can serve to guide their actions to a successful outcome. That being so, they need sources of information that will lead them to believe truths. They have 'on-board' sources, eyes and ears, powers of reasoning, which give them a primary stock of beliefs. It will be highly advantageous to them if they can also tap the primary stocks of their fellows ... that is to say, if they act as informants for each other. On any issue, some informants will be better than others, more likely to supply a true belief ... So any community may be presumed to have an interest in evaluating sources of information; and in connection with that interest certain concepts will be in use ... To put it briefly and roughly, the concept of knowledge is used to flag approved sources of information" (Craig 1990: 11).

If this is along the right lines, 'knowledge' ascriptions have the pragmatic function of recommending sources of information. If one recommends something, one adopts a particular non-doxastic attitude towards it. Consequently, 'knowledge' ascriptions express recommendations, which are a particular sort of non-doxastic attitude. ${ }^{13}$

Here are our NORMAL, HIGH and HIGH* cases in dialogue form:

(29) Ted's friend: How do you know Jack performed the service?

Ted: Well, we saw his hat in the hall, and there was a service in progress. So I know Jack performed the service.

(30) Police: Do you know Jack performed the service?

\footnotetext{
${ }^{13}$ Two clarifications: First, it's plausible that recommending something involves more than adopting a non-doxastic attitude towards that thing. But it certainly seems right that recommending something does involve inter alia adopting a non-doxastic attitude towards that thing. I'm focusing on the non-doxastic attitude aspect of recommendations. Second, what do I mean by the claim that 'knowledge' ascriptions 'function pragmatically' as recommendations? The idea, very roughly, is that this is part of their illocutionary force. A relevant comparison is with 'good' claims. It's plausible that 'good' claims express approval, and one can incorporate that into a standard truth-conditional semantics for 'good' claims by holding that this is part of their illocutionary force.
} 
Dougal: Well, we saw his hat in the hall, and there was a service in progress. But we didn't actually see him. So no, I don't know.

Police: Does Ted know? He was overheard claiming to know in the pub earlier.

Dougal: No he's wrong. Ted doesn't know that.

(31) Police: Do you know Jack performed the service?

Ted: Well, we saw his hat in the hall, and there was a service in progress. But we didn't actually see him. So no, I don't know.

Police: But you were overheard claiming to know in the pub earlier.

Ted: I was wrong. I don't know.

Because 'knowledge' ascriptions express recommendations, there's a straightforward explanation of (29-31). Ted's 'knowledge' ascription in (29) serves to recommend himself as a source of information as to Jack's whereabouts. Dougal's 'knowledge' denial in (30) doesn't serve to recommend Ted as a source of information as to Jack's whereabouts. Consequently, Ted and Dougal and incompatible non-doxastic attitudes. Ted recommends something that Dougal doesn't recommend, and they express those attitudes via their 'knowledge' ascriptions and denials. Similarly, Ted's 'knowledge' self-denial in (31) doesn't serve to recommend Ted as a source of information as to Jack's whereabouts so, again, Ted in (31) and Ted in (29) have incompatible non-doxastic attitudes, and they express those attitudes via their 'knowledge' ascriptions and denials. So contextualists can handle (30-31) by appealing to attitudinal disagreement.

However, attitudinal disagreement only licenses the use of certain disagreement markers. So, for all we've said so far, contextualists can't deal with the following variants on (30-31):

(32) Dougal: What Ted said/thinks/believes is false. Ted doesn't know.

(33) Ted: What I said/thought/believed is false. I don't know.

But, as I'll now argue, we can think of (32-33), along with (30-31), as involving context disagreement. Our earlier cases of context disagreement had the following structure. First, the speakers are fixing the extension of an expression via negotiation. Second, in order to negotiate they utter sentences containing that expression. Third, the speakers disagree about how to fix the extension of the relevant expression. Both (32-33) and (30-31) fit this general structure. If contextualism about 'knows' is right, then the speakers in a context need to negotiate so as to fix the standard in that context. In (30-33) it's common knowledge (or it becomes common knowledge) that Dougal and Ted have good but not conclusive evidence that Jack performed the service. Consequently, the best interpretation 
of the various 'knowledge' ascriptions and denials uttered in (30-33) is that they are uttered in order to fix the standard and not to communicate information about Dougal and Ted's epistemic position (again, that's common knowledge). Dougal's 'knowledge' self-denial and his denial that Ted 'knows' in (30) and (32) can be interpreted as Dougal pushing for standards such that neither he nor Ted meet them, and Dougal's use of the various disagreement markers signal that he is pushing for these higher standards rather than the lower standards he and Ted used in (29). Similarly, Ted's 'knowledge' self-denial in (31) and (32) can be interpreted as Ted pushing for standards such that he doesn't meet them, and his use of the various retraction markers signal that he is pushing for these higher standards rather than the lower standards he and Dougal used in (29). So by appealing to context disagreement contextualists can deal with (32-33) as well as (30-31). ${ }^{14}$ I conclude that the contextualist can deal with the disagreement problem.

\subsection{Varieties of Disagreement (again)}

Objection: If this is along the right lines, the contextualist can deal with the disagreement problem just by appealing to context disagreement. So why bother appealing to attitudinal disagreement?

The lesson of $\$ 2.1$ is that disagreement comes in a number of forms, so it should be expected that our intuition that Dougal disagrees with Ted, and that Ted disagrees with his past self, has more than one source. One might worry that attitudinal disagreement isn't 'real' disagreement if one thinks of disagreement as involving expressing incompatible beliefs, and one may equally well worry it isn't 'real disagreement' if one thinks of disagreement as licensing the use of disagreement markers such as 'What you said/think/believe is false'. Similarly, one might worry that context disagreement isn't 'real' disagreement if one thinks of disagreement as involving any sort if incompatibility in attitudes, whether doxastic or non-doxastic. For these reasons, it would be a mistake for the contextualist to rest content with appealing to context disagreement, just as it would

\footnotetext{
${ }^{14}$ It's worth briefly clarifying how the solution to the disagreement problem proposed here differs from the solution proposed in DeRose (2009: Ch. 4) on which disagreement, whether within a single conversation or across conversations, results in truth-value gaps. The view proposed here is consistent with DeRose's view. But the question of what happens to the truth-values of our claims while we're negotiating over the extensions of various terms that figure in those claims is a vexed one, and it's a question for everyone, not just for the contextualist about 'knows' (it is just as much a question for the contextualist about 'tall'). To my mind, we need to settle the general question before settling the particular question about 'knows'.
} 
be a mistake for her to rest content with appealing to attitudinal disagreement. She can only benefit by drawing attention to the variety of ways in which she can make sense of disagreement.

\section{Concluding Remarks}

Epistemic contextualism faces a number of serious objections and, if they can't be answered, the view should be consigned to history. I don't claim to have dealt with all of the objections here, or even with all of the most serious ones. But I do claim to have dealt with two sorts of objections that have been enormously influential. First, I have argued that epistemic contextualists can deal with what I called the 'linguistic objections'. Contra what these objections purport to show, the expression 'knows' behaves no differently to a number of other context-sensitive expressions. Second, I have argued that they can deal with the disagreement problem. Contra what this objection purports to show, the way that 'knows' behaves in intra- and inter-contextual disagreement reports poses no problem for the epistemic contextualism. Consequently, one can't appeal to the linguistic objections or retraction and disagreement to motivate adopting a non-contextualist semantics for 'knows'. This goes a long way - albeit only part of the way - to rehabilitating epistemic contextualism. ${ }^{15}$

\section{Bibliography}

Barker, C. (2002). The Dynamics of Vagueness. Linguistics and Philosophy 25 (1): 1-36.

Blome-Tillmann, M. (2008). The Indexicality of 'Knowledge'. Philosophical Studies 138 (1):

Brogaard, B. (2008). Moral Contextualism and Moral Relativism. Philosophical Quarterly 58: 385-409.

Brown, J. (2006). Contextualism and Warranted Assertibility Manoeuvres. Philosophical Studies 130 (3): 407-435.

Buckwalter, W. (2010). Knowledge Isn't Closed on Saturday: A Study in Ordinary Language. Review of Philosophy and Psychology 1 (3): 395-406.

Cohen, S. (1999). Contextualism, Skepticism, and the Structure of Reasons. Philosophical Perspectives 13: 57-89.

\footnotetext{
${ }^{15}$ Thanks to Davide Fassio, Michael Hannon, Allan Hazlett and two anonymous reviewers for this journal for extremely helpful feedback on earlier versions of this paper. Research on this paper was assisted by funding from the ERC Advanced Grant Project "The Emergence of Relativism" (Grant No. 339382), a postdoctoral fellowship from the University of Geneva and the Carnegie Trust.
} 
Craig, E. (1990). Knowledge and the State of Nature: An Essay in Conceptual Synthesis. Oxford: Oxford University Press.

DeRose, K. (1992). Contextualism and Knowledge Attributions. Philosophy and Phenomenological Research 52 (4): 913-929. (1995). Solving the Skeptical Problem. Philosophical Review 104: 1-52. (2009). The Case for Contextualism: Knowledge, Skepticism and Context, vol. 1. Oxford: Clarendon.

Fricker, M. (2008). Scepticism and the Genealogy of Knowledge: Situating Epistemology in Time. Philosophical Papers 37 (1): 27-50. (2012). Group Testimony? The Making of a Collective Good Informant. Philosophy and Phenomenological Research 84 (2): 249-276.

Greco, J. (2008). What's Wrong With Contextualism?. Philosophical Quarterly 58 (232): 416436. (2009). Knowledge and Success from Ability. Philosophical Studies 142 (1): 17-26.

Hawthorne, J. (2004). Knowledge and Lotteries. Oxford: Oxford University Press.

Henderson, D. (2009). Motivated Contextualism. Philosophical Studies 142 (1): 119-131.

Huvenes, T. (2012). Varieties of Disagreement and Predicates of Taste. Australasian Journal of Philosophy 90 (1): 167-181.

Kelp, C. (2011). What's the Point of "Knowledge” Anyway? Episteme 8: 53-66.

Kennedy, C. (1999). Projecting the Adjective: The Syntax and Semantics of Gradability and Comparison. New York: Garland.

Kolodny, N. \& MacFarlane, J. (2010). Ifs and Oughts. Journal of Philosophy 107 (3): 115143.

Kornblith, H. (2000). The Contextualist Evasion of Epistemology. Philosophical Issues 10: 24-32.

Lackey, J. (2012). Group Knowledge Attributions. In Brown, J. \& Gerken, M. (eds.), New Essays on Knowledge Ascriptions. Oxford: University Press: 243-269.

Lewis, D. (1979). Scorekeeping in a Language Game. Journal of Philosophical Logic 8 (1): 339-359. (1996). Elusive Knowledge. Australasian Journal of Philosophy 74 (4): 549-567.

Ludlow, P. (2005). Contextualism and the New Linguistic Turn in Epistemology. In Preyer, G. \& Peter, G. (eds.), Contextualism in Philosophy: Knowledge, Meaning, and Truth. Oxford: Oxford University Press: 11-50. 
MacFarlane, J. (2005). The Assessment Sensitivity of Knowledge Attributions. Oxford Studies in Epistemology 1: 197-233.

May, J., Sinnott-Armstrong, W., Hull, J. G. \& Zimmerman, A. (2010). Practical Interests, Relevant Alternatives, and Knowledge Attributions: An Empirical Study. Review of Philosophy and Psychology 1 (2): 265-273.

McKenna, R. (2014). Normative Scorekeeping. Synthese 191 (3): 607-624.

Montminy, M. (2013). The Role of Context in Contextualism. Synthese 190 (12): 23412366.

Neta, R. (2006). Epistemology Factualized: New Contractarian Foundations for Epistemology. Synthese 150 (2): 247-280.

Pritchard, D. (2012). Anti-Luck Virtue Epistemology. Journal of Philosophy 109: 247-279.

Richard, M. (2004). Contextualism and Relativism. Philosophical Studies 119 (1-2): 215-242.

Sosa, E. (2000). Skepticism and Contextualism. Philosophical Issues 10: 1-18.

Stanley, J. (2005). Knowledge and Practical Interests. Oxford: Oxford University Press.

Stephenson, T. (2007). Judge Dependence, Epistemic Modals, and Predicates of Personal taste. Linguistics and Philosophy 30 (4): 487-525.

Stevenson, C. (1944). Ethics and Language. Yale University Press.

Stojanovic, I. (2007). Talking about Taste: Disagreement, Implicit Arguments, and Relative Truth. Linguistics and Pbilosophy 30 (6): 691-706.

Sundell, T. (2011). Disagreements about Taste. Philosophical Studies 155 (2): 267-288.

von Fintel, K. \& Gillies, A. (2009). "Might” Made Right. In Egan, A. \& Weatherson, B. (eds.), Epistemic Modality. Oxford: Oxford University Press: 208-30.

Williamson, T. (2000). Knowledge and its Limits. Oxford: Oxford University Press. 